\title{
Philippe Duhamel, Magali Talandier et Bernard Toulier (dir.), Le Balnéaire. De la Manche au monde
} coll. “Art \& Société”, Presses universitaires de Rennes, 2015, 384 pages Jean-Christophe Gay

\section{OpenEdition}

\section{Journals}

Édition électronique

URL : http://journals.openedition.org/tourisme/1054

DOI : $10.4000 /$ tourisme. 1054

ISSN : 2492-7503

Éditeur

Éditions touristiques européennes

Référence électronique

Jean-Christophe Gay, « Philippe Duhamel, Magali Talandier et Bernard Toulier (dir.), Le Balnéaire. De la Manche au monde », Mondes du Tourisme [En ligne], 11 | 2015, mis en ligne le 01 décembre 2015, consulté le 25 septembre 2020. URL : http://journals.openedition.org/tourisme/1054 ; DOI : https:// doi.org/10.4000/tourisme.1054

Ce document a été généré automatiquement le 25 septembre 2020

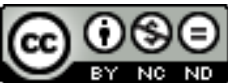

Mondes du tourisme est mis à disposition selon les termes de la licence Creative Commons Attribution - Pas d'Utilisation Commerciale - Pas de Modification 4.0 International. 


\title{
Philippe Duhamel, Magali Talandier et Bernard Toulier (dir.), Le Balnéaire. De la Manche au monde
}

coll. “Art \& Société”, Presses universitaires de Rennes, 2015, 384 pages

\author{
Jean-Christophe Gay
}

\section{RÉFÉRENCE}

Philippe Duhamel, Magali Talandier et Bernard Toulier (dir.), Le Balnéaire. De la Manche au monde, coll. “Art \& Société”, Presses universitaires de Rennes, 2015

1 Théâtre de fameuses rencontres intellectuelles qui ont engendré des centaines de publications, le château de Cerisy, dans la Manche, a accueilli en juin 2013 un colloque sur les bains de mer, thématique probablement méprisée par la plupart de ceux qui ont réfléchi en ce lieu. Autant dire que ce colloque participe d'une reconnaissance des recherches en tourisme. Publié deux ans plus tard, l'ouvrage qui en a été tiré est une réussite sur le plan formel. Imprimé sur papier glacé, il bénéficie d'une belle typographie avec une iconographie en noir et blanc et en couleurs, essentiellement constituée de photographies de grande qualité. On peut féliciter les Presses universitaires de Rennes qui, une fois de plus, montrent leur dynamisme et leur compétence. Nous regrettons cependant le caractère peu pratique des notes en fin d'articles et, pour comble d'infortune, des références en fin d'ouvrage, imposant au lecteur une gymnastique pénible. Voulait-on par cet artifice malheureux donner un caractère plus noble à ces actes ? Des historiens, des historiens de l'art, des architectes, des urbanistes, des géographes, une économiste, un sociologue et un statisticien nous proposent une série de contributions, de valeur très inégale, mais c'est la loi du genre. On pourrait toutefois reprocher aux trois codirecteurs de l'ouvrage de ne pas avoir cherché à resserrer le propos en écartant quelques textes qui ne sont pas au niveau des autres. Toujours est-il que ce livre donne du grain à moudre à tous ceux qui 
s'intéressent à cette conquête touristique des littoraux, attribut de la mondialisation. Nous sommes passés d'un "désir du rivage", pour reprendre la belle formule d'Alain Corbin, à un jouir du rivage, qui touche à peu près toutes les parties de notre planète et les populations.

2 Les lecteurs à la recherche de faits relevant de l'histoire du tourisme seront plus intéressés par la première partie, qui, après un beau texte d'introduction de Bernard Toulier, sur l'architecture du bord de mer en France du XVIII ${ }^{e}$ au XX ${ }^{e}$ siècle, synthèse de ses recherches, et une mise au point de l'historien britannique Allan Brodie expliquant pourquoi on a commencé à se baigner au XVIII ${ }^{e}$ siècle en Angleterre, aborde une série de cas très intéressants : Sainte-Adresse et le littoral normand ; la principauté de Monaco; la mission Racine en Languedoc-Roussillon; le littoral oriental de la Floride ; l'Italie. Signalons dans le texte sur la Floride l'orthographe systématiquement fautive d'Henry Flagler (et non "Flager") qui, avec Henry Plant, est à l'origine de la mise en tourisme de cet État. Saluons l'intérêt de la contribution de nos collègues italiens Valter Balducci et Valentina Orioli sur les villes nouvelles balnéaires italiennes. Remarquons l'apport de Jean-François Pinchon à la compréhension des modèles étrangers qui ont servi aux architectes de la mission Racine. Les lecteurs plus attentifs au présent et aux réflexions conceptuelles préféreront la seconde partie intitulée "Circulation et renouvellement des codes et des pratiques". Mentionnons spécialement les textes de Benjamin Taunay et d'Isabelle Sacareau, respectivement sur les pratiques de plage en Chine et en Inde. Déplorons l'absence de carte pour suivre correctement l'analyse sur le balnéaire à Abu Dhabi. Cette carence cartographique est d'ailleurs un défaut général dans cet ouvrage.

En dépit de quelques imperfections et pour 28 euros seulement, nous préconisons la lecture de cet ouvrage pour mieux connaître le tourisme et réfléchir à l'économie, à l'habiter ainsi qu'aux mobilités qu'il génère.

\section{AUTEURS}

\section{JEAN-CHRISTOPHE GAY}

université Nice Sophia Antipolis 